\title{
High-resolution Computed Tomography for Clinical Imaging of Bone Microarchitecture
}

\author{
Andrew J. Burghardt BS, Thomas M. Link MD, \\ Sharmila Majumdar PhD
}

Published online: 23 February 2011

(c) The Author(s) 2011. This article is published with open access at Springerlink.com

\begin{abstract}
Background The role of bone structure, one component of bone quality, has emerged as a contributor to bone strength. The application of high-resolution imaging in evaluating bone structure has evolved from an in vitro technology for small specimens to an emerging clinical research tool for in vivo studies in humans. However, many technical and practical challenges remain to translate these techniques into established clinical outcomes.

Questions/purposes We reviewed use of high-resolution CT for evaluating trabecular microarchitecture and cortical ultrastructure of bone specimens ex vivo, extension of these techniques to in vivo human imaging studies, and recent studies involving application of high-resolution $\mathrm{CT}$ to characterize bone structure in the context of skeletal disease.

Methods We performed the literature review using PubMed and Google Scholar. Keywords included CT, MDCT, micro-CT, high-resolution peripheral CT, bone microarchitecture, and bone quality.

Results Specimens can be imaged by micro-CT at a resolution starting at $1 \mu \mathrm{m}$, but in vivo human imaging is
\end{abstract}

Each author certifies that he or she has no commercial associations (eg, consultancies, stock ownership, equity interest, patent/licensing arrangements, etc) that might pose a conflict of interest in connection with the submitted article.

A. J. Burghardt, T. M. Link, S. Majumdar ( $\square)$

Musculoskeletal Quantitative Imaging Research Group,

Department of Radiology and Biomedical Imaging,

University of California, San Francisco, Campus Box 2520,

QB3 Building, 2nd Floor, Suite 203, 1700 4th Street,

San Francisco, CA 94158, USA

e-mail: sharmila.majumdar@ucsf.edu restricted to a voxel size of $82 \mu \mathrm{m}$ (with actual spatial resolution of $\sim 130 \mu \mathrm{m}$ ) due to technical limitations and radiation dose considerations. Presently, this mode is limited to peripheral skeletal regions, such as the wrist and tibia. In contrast, multidetector $\mathrm{CT}$ can assess the central skeleton but incurs a higher radiation burden on the subject and provides lower resolution $(200-500 \mu \mathrm{m})$.

Conclusions CT currently provides quantitative measures of bone structure and may be used for estimating bone strength mathematically. The techniques may provide clinically relevant information by enhancing our understanding of fracture risk and establishing the efficacy of antifracture for osteoporosis and other bone metabolic disorders.

\section{Introduction}

The skeleton is composed of cortical and trabecular bone, both contributing to bone strength and the resistance of bone to fracture. The strength of bone and risk of fracture are important outcomes in the study of growth and peak bone accrual, aging, postmenopausal bone loss, cancerrelated bone loss, and for conditions such as diabetes, osteogenesis imperfecta, osteoarthritis, rheumatoid arthritis, and others. Typically, clinical assessment of skeletal health is based on measures of bone mineral density (BMD), usually obtained using dual-energy xray absorptiometry (DXA), a two-dimensional, projection-based radiographic technique that measures integral BMD of both cortical and trabecular bone (areal BMD). In addition to DXA, three-dimensional quantitative CT (QCT) is used to assess BMD. This three-dimensional technique measures volumetric BMD and permits characterization of bone geometry and density as elements of fracture risk. 
Furthermore, QCT can examine cortical and trabecular bone independently.

BMD only explains about $70 \%$ to $75 \%$ of the variance in strength [2], while the remaining variance is due to the cumulative and synergistic effect of factors such as bone macro- and microarchitecture, tissue composition, and microdamage $[30,132]$. In a multicenter fracture intervention trial, the antifracture efficacy of all drugs tested was only partially explained by their effects on BMD [9]. In this context, and specifically in osteoporosis, the concept of bone quality emerged [132]. Bone quality represents different properties of bone to researchers and could encompass one or all of the factors mentioned. Trabecular and cortical bone play important roles in the prediction of bone strength and are affected by age, gender, and metabolic conditions and have varying responses to therapy. Sites containing predominantly trabecular bone, such as the hip, spine, and wrist, are most frequently associated with increased fracture risk [39]. Traditionally, trabecular microarchitecture is assessed from bone biopsies by twodimensional histomorphometry [116], applying stereologic principals to measure trabecular bone volume fraction (the ratio of mineralized bone volume to total volume [BV/ TV]), trabecular thickness (Tb.Th), trabecular separation (Tb.Sp), and trabecular number (Tb.N). On the other hand, cortical bone constitutes about $80 \%$ of total bone mass. In previous studies, cortical thinning [119] and increased cortical porosity [13] were important factors in the assessment of osteoporosis and bone strength. Recently, focus increased on the ultrastructure of cortical bone that can be attributed to resorption spaces, merging of Haversian canals, and clustering of osteons [6,77]. Since the ultrastructure of cortical bone has a major impact on its mechanical properties [131, 152], characterizing cortical ultrastructure is also important in the context of bone strength and prediction of fracture risk. With the advent of improved three-dimensional imaging techniques, such as micro-CT [51, 126], high-resolution peripheral QCT (HR-pQCT) [14, 82], and multidetector CT (MDCT) [73], it is possible to perform in vitro and in vivo imaging of bone across different structural scales from the whole bone to the ultrastructural level.

In a recent publication for the radiographic imaging communities, we reviewed three-dimensional techniques for assessing bone structure in osteoporosis [86]. We described MRI, image processing, and CT, concluding these modalities have the potential to play an important role in imaging three-dimensional trabecular microarchitecture in osteoporosis. In this review, we focus on the development and application of high-resolution CT for quantifying cortical and trabecular bone structure covering specific clinical applications of interest to the orthopaedic research community.
We reviewed (1) the fundamentals of high-resolution CT for evaluating trabecular microarchitecture and cortical ultrastructure, (2) use of micro-CT for studying bone specimens ex vivo, (3) use of MDCT for in vivo human imaging studies, and (4) recent studies using HR-pQCT to characterize bone structure in the context of skeletal disease, particularly its ability to discriminate between subjects with and without fractures and monitor longitudinal response to therapeutic intervention.

\section{Search Strategy and Criteria}

To determine the relevant articles, we used the PubMed (PM) and Google Scholar (GS) search engines. The following list of search phrases was used, with the number of results reported parenthetically: "CT" AND "trabecular bone microarchitecture" (PM: 14; GS: 549); "microCT iliac crest biopsy" (PM: 17; GS: 122); "microct" AND "cortical bone porosity" (PM: 19; GS: 74); "XtremeCT" (PM: 8; GS: 139); "HR-pQCT" (PM: 68; GS: 247); "MDCT" AND "bone structure" (PM: 7; GS: 111); "SR- $\mu$ CT" AND "bone structure" (PM: 8; GS: 82). From these, we selected those articles we believed most relevant.

\section{Fundamentals of CT Imaging}

CT is a three-dimensional radiographic imaging technique. The image formation process begins with the acquisition of sequential radiographic projections captured over a range of angular positions around the object of interest. The cross-sectional field of view is reconstructed using established computational techniques based on radon projection theory [50]. Similar to simple radiography, the reconstructed image's intensity values represent the local radiographic attenuation: a material property related to the object's electron density (atomic number and mass density). The contrast between soft and mineralized tissue in $\mathrm{CT}$ is high, due to the relative electron-dense inorganic component (calcium hydroxyapatite) of the bone matrix [8]. Since the logarithm of the measured absorption scales linearly with the length of material the beam has penetrated, simultaneous quantitative measurements of bone density are possible. Calibration of grayscale linear attenuation to BMD is accomplished by imaging reference phantoms containing objects with known hydroxyapatite concentrations [21, 49].

These principles capture high-resolution images of bone across a range of structural scales. Several classes of CT devices are presently used for high-resolution imaging of trabecular microarchitecture and cortical ultrastructure (Table 1). Techniques with spatial resolution between 1 
Table 1. Descriptive summary of high-resolution CT technologies available

\begin{tabular}{|c|c|c|c|c|c|c|c|}
\hline Modality & References & Primary manufacturers & $\begin{array}{l}\text { Skeletal } \\
\text { sites }\end{array}$ & $\begin{array}{l}\text { Field of } \\
\text { view size } \\
(\mathrm{mm})\end{array}$ & $\begin{array}{l}\text { Voxel } \\
\text { size }(\mu \mathrm{m})\end{array}$ & $\begin{array}{l}\text { Effective } \\
\text { dose }\end{array}$ & $\begin{array}{l}\text { Typical } \\
\text { scan time }\end{array}$ \\
\hline Micro-CT & $\begin{array}{l}55,129 \\
\quad 135,151\end{array}$ & $\begin{array}{l}\text { GE Heathcare (Waukesha, WI) } \\
\text { Scanco Medical AG } \\
\text { (Brüttisellen, Switzerland) } \\
\text { Siemens (New York, NY) } \\
\text { SkyScan (Kontich, Belgium) } \\
\text { Xradia (Pleasanton, CA) }\end{array}$ & $\begin{array}{l}\text { Specimens } \\
\text { Biopsies } \\
\text { (ex vivo) }\end{array}$ & $2-100$ & $\begin{array}{l}0.3-100 \\
\quad \text { (isotropic) }\end{array}$ & NA & $\begin{array}{l}30 \text { minutes } \\
\text { to } 3 \text { hours }\end{array}$ \\
\hline MDCT/fp-vCT & $\begin{array}{c}5,41,43,44 \\
\quad 69,70,73, \\
85,118,124\end{array}$ & $\begin{array}{l}\text { GE Heathcare (Waukesha, WI) } \\
\text { Philips (Amsterdam, The } \\
\text { Netherlands) } \\
\text { Siemens (New York, NY) } \\
\text { Toshiba Corp (Tokyo, Japan) }\end{array}$ & $\begin{array}{l}\text { Specimens } \\
\quad \text { (ex vivo) } \\
\text { Spine } \\
\text { Femur } \\
\text { Forearm } \\
\quad \text { (in vivo) }\end{array}$ & $100-250$ & $\begin{array}{l}156-300 \\
\quad \text { (in plane) } \\
300-500 \text { (slice } \\
\text { thickness) }\end{array}$ & $0.1-5 \mathrm{mSv}$ & $<30$ seconds \\
\hline HR-pQCT & $14,82,130$ & $\begin{array}{l}\text { Scanco Medical AG } \\
\text { (Brüttisellen, Switzerland) }\end{array}$ & $\begin{array}{l}\text { Specimens } \\
\quad \text { (ex vivo) } \\
\text { Distal radius } \\
\text { Distal tibia } \\
\quad \text { (in vivo) }\end{array}$ & 126 & $\begin{array}{l}\text { 41-123 } \\
\quad \text { (isotropic) }\end{array}$ & $3-4 \mu \mathrm{Sv}$ & 3 minutes \\
\hline
\end{tabular}

$\mathrm{NA}=$ not applicable; MDCT $=$ multidetector $\mathrm{CT} ;$ fp-vCT $=$ flat-panel volumetric $\mathrm{CT}$; HR-pQCT $=$ high-resolution quantitative $\mathrm{CT}$.

and $100 \mu \mathrm{m}$ are referred to as micro-CT and may replace tedious serial staining procedures required by histomorphometric analysis of thin sections and offer the possibility of longitudinal in vivo investigations in small animals, such as mice and rats. Many early micro-CT approaches used synchrotron radiation (SR) [59], which is still the method of choice for ultrahigh-resolution applications. The use of desktop laboratory scanners equipped with xray tubes is much more convenient than performing an experiment at one of the few synchrotron facilities available worldwide. Initial and ongoing university-based research in the past decade has led to the development of a variety of commercial xray tube-based micro-CT scanners (Table 1).

Application of standard whole-body MDCT to imaging trabecular bone in the central and peripheral skeleton was investigated at several research institutes [5, 43, 58, 70, 73]. Compared to standard two-dimensional QCT, volumetric MDCT imaging studies use higher-dose acquisition protocols ( $3 \mathrm{mSv}$ versus $0.06-0.3 \mathrm{mSv}$ ) with a higher in plane resolution $(200-300 \mu \mathrm{m}$ versus $500-1000 \mu \mathrm{m})$ and smaller slice thickness and spacing $(500 \mu \mathrm{m}$ versus 1-10 mm). Recently, a standard MDCT gantry was combined with two-dimensional flat panel detector technology to provide rapid continuous acquisitions at high isotropic spatial resolution $[60,124]$. In the last 5 years, a highresolution, limited-field-of-view CT device became commercially available for dedicated imaging of bone structure in the peripheral skeleton [14, 80, 82, 97]. The HR-pQCT imaging system consists of a microfocus xray source and high-resolution charge-coupled device (CCD) detector that can produce tomographic images with a nominal resolution as high as $41 \mu \mathrm{m}$ for a $12.6-\mathrm{mm}$ field of view.

\section{Micro-CT}

Micro-CT has achieved widespread use in the laboratory for rapid, nondestructive imaging of bone specimens [47, 51, 108] and noninvasive imaging in animal models [54, 148]. The pervasive use of this technology at many research institutes invested in bone science research has widely eclipsed traditional histomorphometry for evaluating bone microarchitecture. However, micro-CT does not provide direct information on cellular function and remodeling activity, which continues to be the domain of bone histology.

Conventional laboratory micro-CT typically uses a conebeam, polychromatic xray source, which produces photons spanning a broad range of energies. In contrast, SR micro$\mathrm{CT}$, only available at a limited number of particle accelerator facilities worldwide, is typically performed using a parallel, monochromatic beam [72, 83, 127, 141]. While the first commercial micro-CT scanner consisted of a singlerow 512-pixel detector [126], modern scanners employ areal CCD detectors up to 11 megapixels and are capable of acquiring projection data for more than 1000 slices simultaneously [129, 135, 151]. Dedicated specimen ex vivo scanners are typically designed with the specimen oriented 
on a high-resolution motorized stage for translation and rotation. In this scenario, the source and detector remain in a fixed position during the scan, while the specimen rotates in the field of view. Conversely, preclinical micro-CT systems designed for in vivo imaging of small animals utilize a fixed gantry with the xray source and detector rotating and translating about the field of view [54, 147].

Analogous to clinical QCT, the grayscale attenuation values of reconstructed micro-CT images can be converted to hydroxyapatite concentration. Various calibration procedures based on idealized phantoms or theoretical calculations were established to derive relations between attenuation and BMD [21, 72, 102, 107, 110, 113]. However, micro-CT imaging is subject to xray scattering (SR and polychromatic micro-CT) and beam-hardening effects (polychromatic micro-CT) that can introduce nonnegligible error in the depiction of mineralization that is spatially variant and dependent on the geometry and composition of the object imaged [48, 79, 102]. Methods to minimize beam-hardening effects in conventional micro-CT include xray filtration to block "soft" low-energy xrays [102] and empirical corrections based on phantom measurements [21]. Using these procedures, apparent BMD and tissue level mineral density can be accurately measured $\left(r^{2}=0.78-0.99\right)$ in specimens of similar size and composition [21, 79].

Morphometric indices analogous to classical histomorphometry can be calculated from micro-CT images of trabecular and cortical bone. Comparison of structural parameters of specimens scanned with these systems and mechanical testing suggest the amount of bone and the architecture of trabecular bone contribute to mechanical strength [57]. Advanced image-processing methodologies are used to quantify trabecular bone microarchitecture beyond measures of bone volume fraction (BV/TV). Specifically, direct three-dimensional measures of mean distances and measures of structural heterogeneity are used to characterize trabeculae and marrow spaces [64, 65] (Fig. 1). The degree of anisotropy, a measure of the degree of structural orientation of the trabecular network, can be calculated from the principal structural directions calculated by the mean intercept length techniques [63] and is highly related to the directional dependence of bone's biomechanical properties [115]. A measure of the structural connectedness was also adapted to bone, based on the Euler number [114]. The shape of the trabecular structure is characterized using the structure model index (SMI), an index of surface convexity that estimates the degree to which the structure consists of rod-like or plate-like elements [66]. Furthermore, several groups developed algorithms to decompose the trabecular structure to independently quantify the volume and scale of rod-like and plate-like elements $[92,117,139]$.
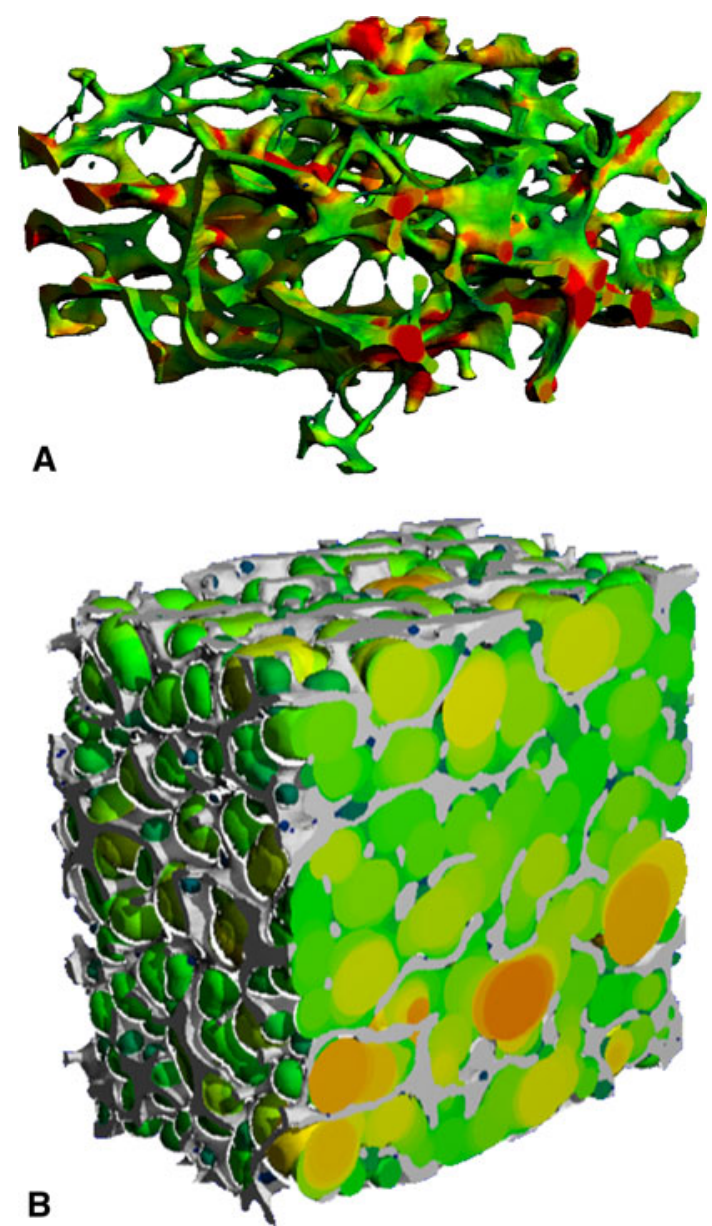

Fig. 1A-B Three-dimensional micro-CT images (16- $\mu \mathrm{m}$ isotropic voxel size) show (A) the spatial distribution of thickness and (B) the spatial distribution of the diameters of the intertrabecular marrow space in two specimens of human trabecular bone calculated by the direct three-dimensional distance transformation method of Hildebrand and Ruegsegger [65].

The ultrastructure of cortical bone is an important determinant of bone strength $[128,131]$, critical in fracture initiation and propagation [146], and known to change with age [37], disease [7], and therapy [11]. Volumetric and morphologic characterization of the cortical ultrastructure has predominantly focused on Haversian and Volkmann canal network of cadaveric femoral neck specimens [13, 32, 36, 38, 153]. Resolution improvements heralding the evolution of nano-CT (CT with submicron resolution) recently paved the way for a complete evaluation of cortical bone ultrastructure, including the distribution of osteocyte lacunae [131, 146].

While volumetric density and microarchitecture information provide improved fracture risk prediction and some explanation for treatment efficacy, more direct estimates of bone mechanical strength that inherently account for geometry, microarchitecture, and even composition are the ultimate goal for improving fracture risk prediction and 
management of osteoporosis. Computational modeling approaches were introduced to take advantage of the detailed information in high-resolution images of bone. Finite element analysis (FEA) is a common computational tool in engineering fields, critical to design and failure analysis. Applied to high-resolution images of bone, the apparent biomechanical properties (stiffness, elastic modulus) of a biologically complex microstructure are computed by decomposing the structure into small cubic elements (the voxels) with assumed mechanical properties [109, 143] (Fig. 2). Numerous studies have utilized micro-FEA techniques to investigate the micromechanics of bone strength, failure, and relation to bone microarchitecture [81, 142].

As an ex vivo imaging modality, the application of micro-CT to clinical research is limited to examining small bone biopsy specimens. There are numerous data over the last 20 years characterizing age, gender, and anatomic differences in cadaveric specimens of bone $[13,45,52,64$, $67,68,94]$. Clinical applications generally preclude access to the most relevant sites, such as the spine and proximal femur. Accordingly, a minimally invasive bone biopsy is typically acquired from the iliac crest [75]. Trabecular microarchitecture at the iliac crest reflects vertebral fracture status [56, 74] and changes after the onset of menopause [1]. Quantification of bone structure from iliac crest biopsies is also an important end point in longitudinal

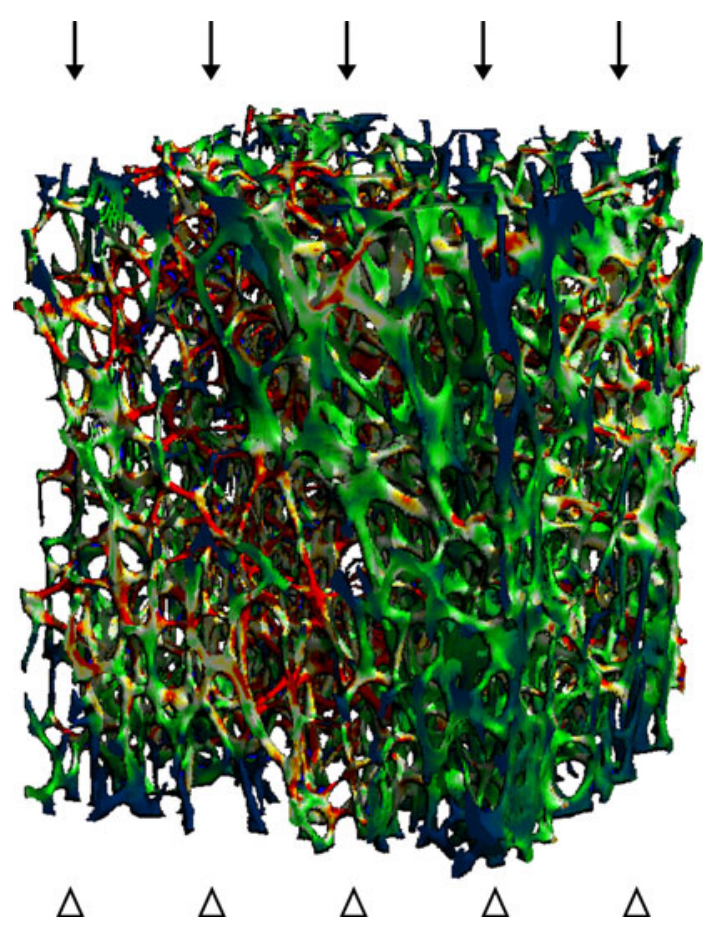

Fig. 2 A micro-CT image shows the distribution of stresses in a human vertebral trabecular bone specimen under a simulated $1 \%$ compressive strain by micro-FEA. Red areas correspond to the locations of highest stress and blue to the areas of low stress. $\mathrm{FEA}=$ finite element analysis. drug efficacy studies of parathyroid hormone [33, 53, 76, 121], strontium ranelate [3], and various bisphosphonates [11, 12, 46, 112, 120, 122, 123]. Borah et al. [11] recently reported major ultrastructural changes to the cortical bone of the iliac crest after 5 years of treatment with risedronate. Despite the resolution advantages of in vitro imaging studies, the invasiveness of the procedure, inherent variability in specimen collection [28, 29], and the limited correlation to bone quality at clinically relevant sites for fragility fracture (proximal femur, lumbar spine, distal radius) [35] are drawbacks to the clinical application of micro-CT.

\section{MDCT}

MDCT is a clinical CT technique available in most diagnostic imaging departments, using scanners from a number of manufacturers (Table 1). Therefore, a dedicated scanner is not required. The spatial resolution of this technique is limited, with an in-plane resolution ranging from 150 to $300 \mu \mathrm{m}$ and a minimum slice thickness of around $300 \mu \mathrm{m}$. These spatial resolutions are above trabecular dimensions, and imaging of individual trabeculae is subject to considerable partial-volume effects. However, given the larger size of intertrabecular spaces, trabecular bone parameters obtained with this technique are observed to correlate moderately well with those determined by contact radiography and micro-CT of bone specimens $(\mathrm{r}=0.53-0.70)$ [71, 91], as well as micro-CT ( $\mathrm{r}=0.44-0.99)$ [43, 44, 69, $70,85,118]$. The advantage of the MDCT technique is that central regions of the skeleton critically relevant to osteoporosis and fracture risk assessment, such as the spine [70, $73,85]$ and proximal femur [5, 43], can be visualized. However, to achieve adequate spatial resolution and image quality, the required radiation exposure is substantial, offsetting the technique's applicability in clinical, routine, and scientific studies (Table 1). High-resolution CT protocols are typically associated with an effective dose of approximately $3 \mathrm{mSv}$ (1.5 years of natural background radiation), several orders of magnitude greater than standard DXA or HR-pQCT (4-13 $\mu \mathrm{Sv})$ and an order of magnitude higher than standard two-dimensional QCT (0.06-0.3 mSv) [41].

While early MDCT systems used for bone structure imaging typically consisted of four to 16 rows of detector elements [73], modern systems have 64 to 320 rows [69]. Most recently, high-resolution areal CCD detectors have been combined with a standard clinical CT gantry to provide substantial improvements in scan time and resolution [124]. In each case, the tomographic acquisition is performed with the subject lying supine on the scan table within the gantry. The xray source and detector ensemble continuously rotate about the field of view while the gantry 
translates along the rotational axis, effectively producing a helical series of projections [78]. Simultaneous calibration of Hounsfield units to mineral density is typically accomplished by placement of a solid hydroxyapatite phantom below the patient [49].

The analysis of trabecular microarchitecture from MDCT and flat-panel volumetric CT image data primarily involves the application of traditional histomorphometry [5, 17, 43, 70, 118], where BV/TV, Tb.N, Tb.Th, and $\mathrm{Tb} . \mathrm{Sp}$ are calculated two-dimensionally using plate model assumptions [116]. In contrast, Ito et al. [73] used direct three-dimensional measures of trabecular dimensions, connectivity, and SMI in a MDCT study of the lumbar spine, finding a strong correlation $(\mathrm{r}=0.98)$ between $\mathrm{BV} /$ TV measured by micro-CT and MDCT. Other specialized measures of trabecular dimensions using the fuzzy distance transform (which does not require a threshold binarization process) have been proposed by Krebs et al. [85].

To date, in vivo human studies using MDCT to assess bone structure are limited due to radiation dose concerns. Ito et al. [73] demonstrated SMI and BV/TV measured from MDCT images of the lumbar spine provided superior fracture discrimination to areal BMD by DXA. Graeff et al. [58] showed teriparatide treatment effects are better monitored by architectural parameters of the spine obtained through MDCT than by BMD (Fig. 3). In a cross-sectional cohort study of adolescent girls with and without anorexia nervosa, Bredella et al. [17] observed diminished trabecular microarchitecture at the distal radius in subjects with anorexia nervosa compared to controls, despite no differences in lumbar areal BMD. In a companion study, Lawson et al. [89] observed the abnormal trabecular microarchitecture in these patients are predicted by IGF-1, leptin, and androgen levels, with positive correlations $(\mathrm{r}=0.32-0.72)$ to BV/TV, Tb.Th, and Tb.N.

\section{HR-pQCT}

A dedicated extremity imaging system designed for trabecular-scale imaging is currently available from a single manufacturer (XtremeCT; Scanco Medical AG, Brüttisellen, Switzerland). This device has the advantage of a higher signal-to-noise ratio and spatial resolution (nominal isotropic voxel dimension of $82 \mu \mathrm{m}$ ) when compared to MDCT. Furthermore, the radiation dose is lower when compared to whole-body CT and does not involve critical, radiosensitive organs in skeletally mature adults. There are several disadvantages to this technology. It is limited to peripheral skeletal sites and provides no direct insight into bone quality in the lumbar spine or proximal femur, common sites for osteoporotic fragility fractures. Additionally, there are currently a limited number of devices installed globally, which are primarily located at major research institutions with few available in clinical radiology departments.
Fig. 3A-D In vivo MDCT images of the vertebral body show three-dimensional reconstructions (A) pre- and (B) postteriparatide therapy for 6 months, (C) 12 months, and (D) 24 months. Images provided by and printed with permission of Claus C. Glüer, Medizinische Physik, Klinik für Diagnostische Radiologie, Universitätsklinikum Schleswig Holstein-Campus Kiel, Kiel, Germany. MDCT $=$ multidetector CT.
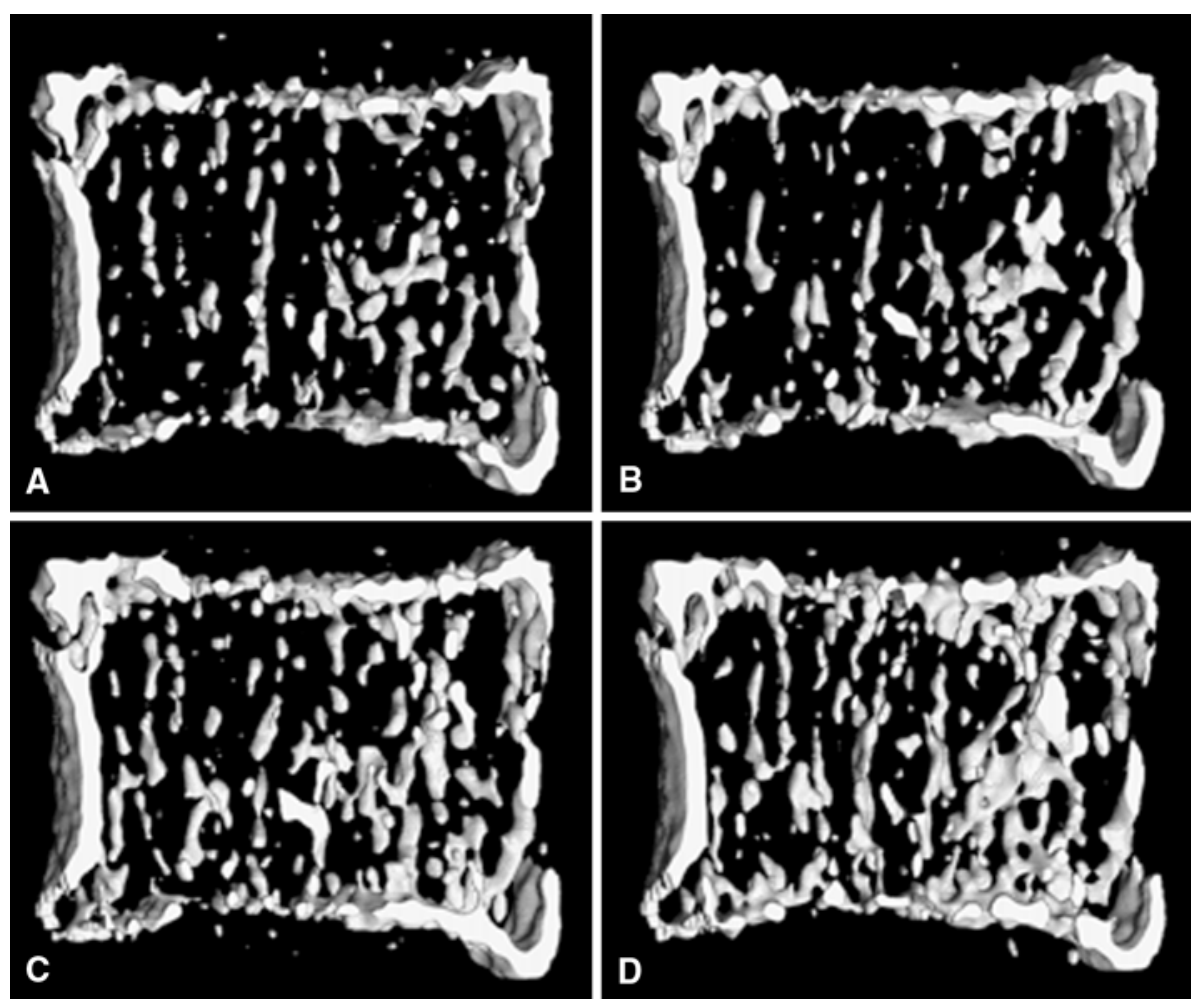
Fig. 4A-B Scout acquisition is used to define the HR-pQCT scan region for (A) the distal radius and (B) the distal tibia. The solid green region corresponds to the imaging location and consists of 110 slices spanning $9.02 \mathrm{~mm}$ longitudinally. In the radius the scan region is fixed $9.5 \mathrm{~mm}$ proximal from the midjoint line, while in the tibia the scan region is $22.5 \mathrm{~mm}$ proximal from the tibial plafond. HR-pQCT $=$ high-resolution peripheral quantitative CT.
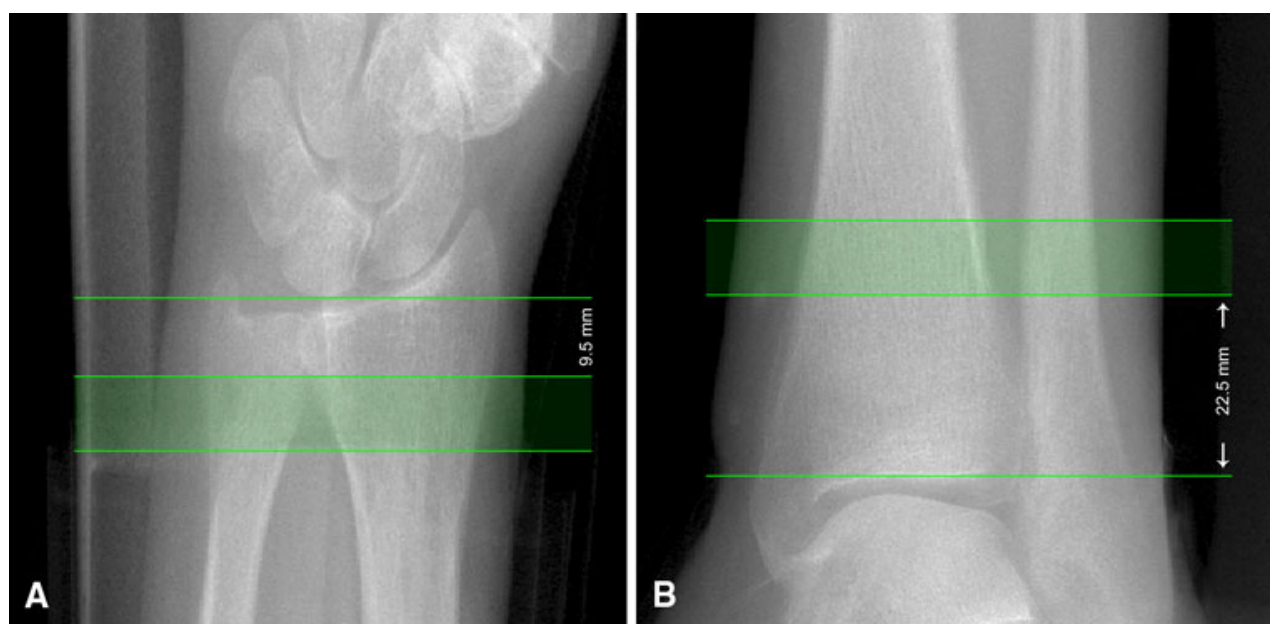

In HR-pQCT, a standard protocol recommended by the manufacturer is utilized for most studies [14, 82]. The patient's forearm or ankle is immobilized in a carbon fiber cast fixed within the gantry of the scanner. A single scout projection image of the distal radius or tibia is acquired to define the tomographic scan region. This scout image is acquired at an AP orientation at the wrist and at an oblique $\left(45^{\circ}\right)$ anterolateral-posteromedial orientation at the ankle. This tomographic region spans $9.02 \mathrm{~mm}$ in length (110 slices) and is localized to a fixed offset proximal from either the radial or tibial midjoint line and extends proximally. The offset is $9.5 \mathrm{~mm}$ in the radius and $22.5 \mathrm{~mm}$ in the tibia (Fig. 4). This method does not account for differences in bone length and may be a confounding source of variability in cross-sectional studies [16]. In the radius, the default axial scan location partially includes the most common site for fracture and location, where the bone microstructure is most strongly correlated to experimental strength of the forearm under a simulated falling load [106].

There are several different protocol modifications for developmental studies in children and adolescents [26, 84] to account for patient size and age-related changes in bone length and to avoid radiation exposure to the epiphyseal growth plate and inclusion of provisional mineralized tissues from this region. In a cross-sectional study of age- and gender-related differences in the microarchitecture of the distal forearm of adolescents, Kirmani et al. [84] used a fixed offset $(1 \mathrm{~mm})$ with respect to the proximal extent of the distal epiphyseal growth plate of the radius. In contrast, Burrows et al. [26] selected a region offset of $8 \%$ of the total tibial length proximal to the tibial endplate. While there are a number of studies underway investigating other scan locations in adults, including more proximal sites dominated by cortical bone, the internal configuration of the XtremeCT gantry prohibits the positioning of true diaphyseal sites in the radius or tibia within the limited $15-\mathrm{cm}$ longitudinal range of the source-detector ensemble.
The reconstructed images are analyzed using a standard protocol provided by the manufacturer. The operator chaperones a semiautomated contouring process to identify the periosteal boundary and segment the cortical and trabecular compartments [42]. The trabecular bone structure is extracted using an edge enhancement and threshold procedure [88]. While the importance of threshold selection for morphometric analysis is well described for other CT devices [61], few studies to date investigate threshold effects or propose new methods for HR-pQCT [23, 42]. The default compartmental and structural segmentation provides the basis for the subsequent densitometric, morphometric, and biomechanical analyses. For subjects with very thin or highly porous cortical bone, this segmentation procedure may fail to capture the cortical structure [42, 80]; therefore, more sophisticated autocontouring techniques that operate on the fine-structure segmentation have been proposed [18, 23]. For the XtremeCT, reproducibility of densitometric measures is very high (coefficient of variation $<1 \%$ ), while biomechanical and morphometric measures typically have a coefficient of variation of $4 \%$ to $5 \%[14,80,82,100,105]$.

The linear attenuation values of the tomographic images are converted to hydroxyapatite mineral densities using a beam-hardening correction and phantom calibration procedure previously described for the ex vivo micro-CT system [21]. Based on this calibration, volumetric BMD is determined independently for cortical and trabecular bone compartments using the segmentation process described previously. HR-pQCT images are used to derive surrogate measures of areal BMD in the ultradistal radius [22]. This technique is associated with a high level of agreement $\left(r^{2}>0.8\right)$ with multiple clinical DXA devices.

Unlike MDCT, which has a large slice thickness relative to the in-plane resolution, the high isotropic resolution of HR-pQCT $(82 \mu \mathrm{m})$ permits direct three-dimensional assessment of intertrabecular distances. These measures 
were validated against micro-CT gold standards [23, 93, 97]. From the binary image of the extracted trabecular structure, three-dimensional distance transformation techniques are used to calculated trabecular number [65]. While the intertrabecular distances are large compared to the voxel dimension, the average trabecular thickness $(100-150 \mu \mathrm{m})$ is only one to two voxels wide. Accordingly, direct measures of thickness and bone volume are complicated by considerable partial-volume effects. In the standard analysis protocol, BV/TV is derived from the trabecular volumetric BMD, assuming a fixed mineralization of $1200 \mathrm{mg}$ hydroxyapatite per $\mathrm{cm}^{3}$ for compact bone $(\mathrm{BV} / \mathrm{TV}=\mathrm{Tb} . \mathrm{BMD} / 1200)$. Trabecular BMD is determined by calculating the mean mineral density of the full medullary compartment. From the direct measure of Tb.N and the densitometrically derived BV/TV, Tb.Th and $\mathrm{Tb} . \mathrm{Sp}$ are derived using standard stereologic relations, assuming plate model geometry $[87,116]$.

There are several potential concerns with this approach. First, Sekhon et al. [134] documented substantial errors in the measurement of trabecular BMD related to biologically relevant variations in cortical thickness and the magnitude of trabecular BMD itself. This may be related to xray scatter effects and residual beam-hardening artifacts. These errors are primarily a concern for cross-sectional studies, when cortical thickness and trabecular BMD may span a broad range. It is less of a concern in longitudinal studies, where the percent of change as the primary end point, such as age-, disease-, and therapy-related changes in cortical thickness and trabecular BMD, is comparatively small. Second, the assumption of a fixed-matrix mineralization is inconsistent with the established action of many common antifracture therapeutics [10]. Changes in matrix mineral density is expected to cause an increase in BMD, irrespective of bone volume changes, and result in an overestimation of BV/TV and propagate error to the derivative measures of $\mathrm{Tb}$.Th and Tb.Sp, confounding any actual therapy-related effect on trabecular bone volume and structure.

Several studies investigate other measures of bone microarchitecture and topology from HR-pQCT images, including connectivity, SMI, and anisotropy; however, there is mixed evidence of their reliability at in vivo resolutions [23, 93, 97, 136]. Recently, more sophisticated approaches to cortical bone segmentation have been proposed [18] that allow direct three-dimensional assessment of cortical thickness and quantification of cortical ultrastructure (Fig. 5), including intracortical porosity and canal diameter [24, 111]

The ability of HR-pQCT to resolve the trabecular microarchitecture and a level of the cortical ultrastructure lends itself to calculating direct estimates of bone strength by voxel-based micro-FEA. For HR-pQCT scans of the distal radius and tibia, this is typically used to estimate strength under uniaxial compression, which approximates to the common loading condition for Colles' fracture of the radius [106] and normal gaited loading for the tibia. This technique was validated against both higher-resolution models (based on micro-CT images) and empirical measures of strength $[93,99]$. The application of micro-FEA is primarily performed assuming homogeneous material
Fig. 5A-D (A, B) Cross-sectional HR-pQCT images through the distal radius show two individuals with identical areal BMD by DXA at the ultradistal radius but substantial differences in trabecular and cortical structure. (C, D) Three-dimensional renderings of the cortical and trabecular bone compartments and intracortical porosity (highlighted in red) were segmented using software described by Burghardt et al. [19]. HR-pQCT = high-resolution peripheral quantitative $\mathrm{CT}$; $\mathrm{BMD}=$ bone mineral density; DXA =dual-energy xray absorptiometry.
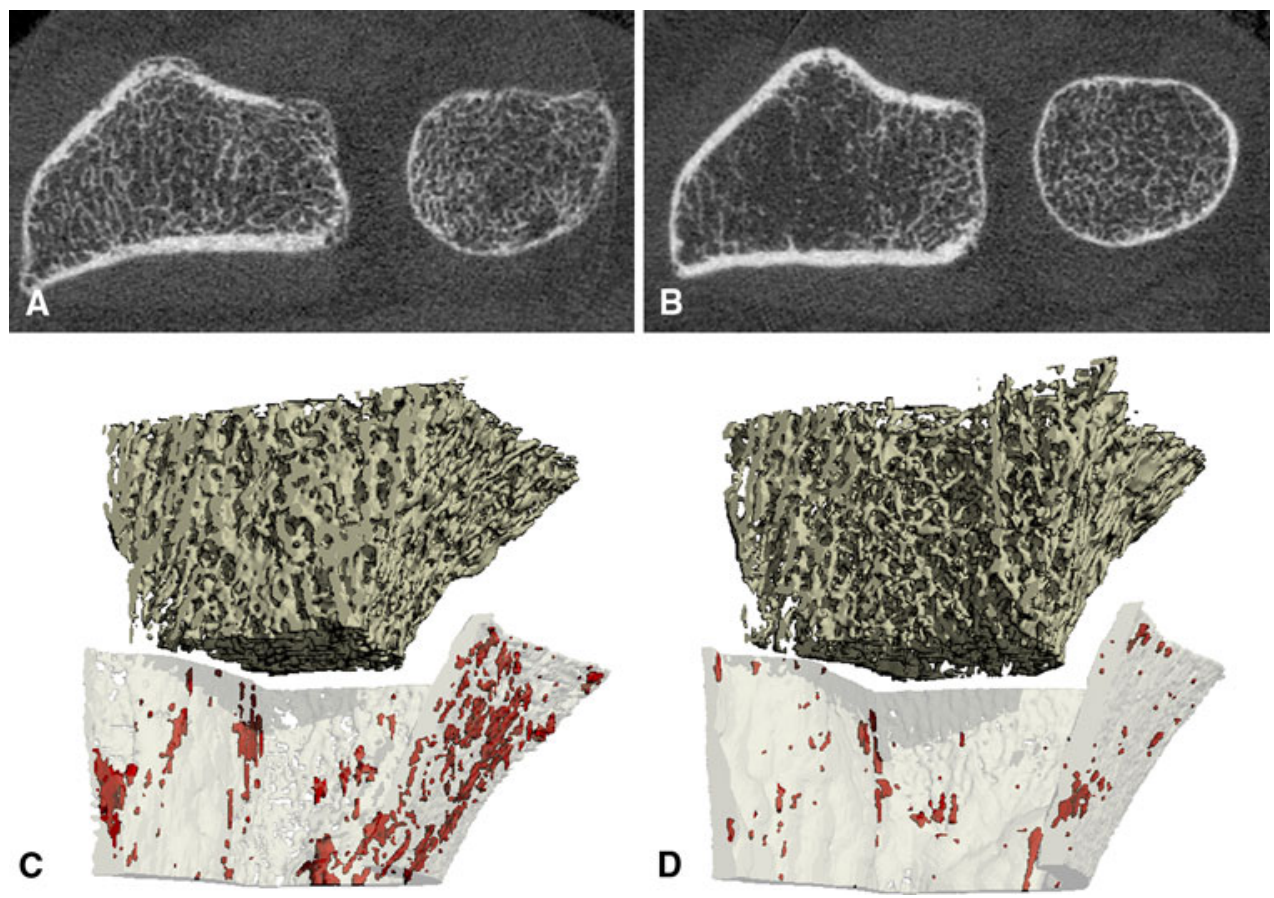
properties $[15,24,40,93,99,105]$, although it is also possible to produce models with material properties scaled according to mineralization $[95,99]$. In addition to wholebone mechanics, micro-FEA can be used to determine the relative load distribution between cortical and trabecular compartments [98] and estimate mechanical implications of specific structural features, such as the resolvable cortical ultrastructure [24].

For clinical investigations into longitudinal changes in HR-pQCT-derived measures of bone quality, it is critical baseline and followup scans be matched, since bone structure and geometry vary substantially along the axial direction [16]. Operator positioning for followup scans are aided by visual reference to the positioning of the baseline scan. Furthermore, postprocess image registration is performed to ensure comparable regions of interest are used for the image analysis. The manufacturer provides software that matches slices based on the periosteal cross-sectional area and limits the analyzed region to the slices common in baseline and followup [87]. Alternatively, MacNeil and Boyd [100] demonstrated three-dimensional image registration techniques can provide improved short- and medium-term reproducibility when compared to the default slice-matching approach. This approach may be more appropriate in longitudinal studies (long-term studies, anabolic therapy trials) where periosteal apposition would confound registration based strictly on cross-sectional area. As discussed earlier, the challenge in obtaining meaningful results in longitudinal studies in children or adolescents experiencing rapid growth is not trivial and requires careful consideration of standardized procedures for scan positioning and analysis [26, 101].

There is a growing body of literature featuring HR-pQCT assessment of bone quality. The first crosssectional studies by Boutroy et al. [14] and Khosla et al. [82] reported gender-specific, age-related differences in trabecular bone microarchitecture. Several centers have observed age-related differences in micro-FEA estimates of bone strength in normative cross-sectional cohorts [24, 40, 96]. Furthermore, Burghardt et al. [24] and Macdonald et al. [96] demonstrated the ability of HR-pQCT to detect dramatic age-related differences in cortical porosity in females using new techniques for the analysis of cortical ultrastructure [19]. A microstructural basis for ethnicityrelated differences in bone strength between East Asian and white women was reported in two studies [149, 150]. Sornay-Rendu et al. [137] suggested cortical and trabecular morphology provided additional fracture discrimination independent of areal BMD in osteopenic women. In the same cohort, Boutroy et al. [15] showed micro-FEA mechanical measures provided additional discriminatory power between osteopenic women with and without distal radius fractures. While the initial focus was predominantly related to fracture discrimination in postmenopausal osteopenia and osteoporosis [15, 103, 104, 137, 138, 140, 144, 145], a number of studies have utilized HR-pQCT to investigate developmental changes in bone quality and fracture risk [27, 34, 84], as well as secondary causes of bone loss [4, 20, 31, 62, 90].

Most recently, data from the first HR-pQCT single- and multicenter longitudinal trials were published. In a multicenter, head-to-head, randomized, placebo-controlled trial of denosumab (a RANKL inhibitor) and alendronate (a bisphosphonate), Seeman et al. [133] reported more pronounced antiresorptive efficacy with denosumab than alendronate. In particular, cortical thickness was preserved or improved at the radius and tibia with either treatment, while cortical bone loss progressed in the control group. Burghardt et al. [25] reported similar cortical bone changes and additionally showed a preservation of compressive bone strength by micro-FEA after 24 months of alendronate treatment. Longitudinal microarchitectural changes also occurred with strontium ranelate [125] and teriparatide [95].

\section{Discussion}

With the advent of new imaging equipment, imageprocessing methods, and mathematical modeling techniques, the importance of trabecular microarchitecture and cortical ultrastructure in the context of bone strength and fracture risk has received considerable attention. This review provided the essential background of high-resolution $\mathrm{CT}$ techniques now in use for clinical skeletal research and summarized the important clinical applications of this technology reported to date.

In focusing on the clinical applications of CT imaging, we did not directly cover a number of important applications of this technology in basic skeletal research. In particular, we did not review (1) numerous ex vivo cadaveric studies conducted to investigate structure-function relationships in cortical and trabecular bone; (2) preclinical imaging studies in animal models of disease, genetic intervention, and environmental effects on skeletal health; and (3) analysis of microarchitecture using texture analysis. Furthermore, it is important to recognize other imaging modalities, such as high-resolution projection radiography, MRI, and phase-contrast xray imaging, may also be used to assess bone microarchitecture. This review did not cover the substantial body of literature on these subjects.

Ex vivo micro-CT is the longest-standing technology used for nondestructive three-dimensional imaging of bone microstructure. Micro-CT scanners resolve the cortical and trabecular structure of human bone specimens and are used to evaluate aspects of bone quality in the context of skeletal disease and therapeutic interventions. However, 
their clinical utility is limited to small biopsy samples, typically taken from the iliac crest.

Translation of these techniques to in vivo imaging modalities, such as the MDCT and HR-pQCT, are subject to technical limitations related to image quality, radiation dose considerations, and subject motion. They provide images at resolutions approximately equal to $\mathrm{Tb}$. Th (HR-pQCT) or intertrabecular distances (MDCT). Furthermore, while MDCT has the advantage of being able to image central skeletal sites, such as the spine and proximal femur, the images represent trabecular texture more than a true visualization of the individual trabecular structure. Similarly, HR-pQCT may not resolve the finest trabeculae or the complete scale of cortical ultrastructure features. Despite the challenges and limitations facing current in vivo CT imaging technologies, morphologic and biomechanical indices determined from these techniques correlate well with micro-CT [73, 97].

Finally, we demonstrated trabecular microarchitecture and cortical ultrastructure measured in vivo show age-, gender-, and race-dependent differences and provide improved fracture discrimination. Early longitudinal HR-pQCT observations suggest it is possible to detect structural changes induced by treatment. Ongoing studies and new results from therapeutic trials will provide a clearer indication as to whether trabecular microarchitecture and cortical ultrastructure measured using these in vivo methods will play a role in further understanding the affect of aging, disease, and interventions on skeletal health.

To date, there are no prospective fracture trials or large therapeutic trials used to draw conclusions regarding the role of in vivo assessment of trabecular microarchitecture and cortical ultrastructure in predicting bone strength and fracture status. These studies are warranted, and it would greatly enhance the field to establish a new set of diagnostic biomarkers that complement or improve upon areal BMD measured by DXA. The primary obstacles to achieving this goal are the substantial cost of large-scale human studies, the limited dissemination of the technology to clinical centers, the minimal standardization of image acquisition and image-processing protocols, and a lack of crosscalibration and quality control procedures (including standardized subject motion detection) for reliable data pooling in multicenter trials. Efforts to overcome the calibration issues, standardization, and multicenter comparative studies are needed to lay the groundwork for future large-scale multicenter trials and prospective studies.

Open Access This article is distributed under the terms of the Creative Commons Attribution Noncommercial License which permits any noncommercial use, distribution, and reproduction in any medium, provided the original author(s) and source are credited.

\section{References}

1. Akhter MP, Lappe JM, Davies KM, Recker RR. Transmenopausal changes in the trabecular bone structure. Bone. 2007;41: 111-116.

2. Ammann P, Rizzoli R. Bone strength and its determinants. Osteoporos Int. 2003;14(Suppl 3):S13-S18.

3. Arlot ME, Jiang Y, Genant HK, Zhao J, Burt-Pichat B, Roux JP, Delmas PD, Meunier PJ. Histomorphometric and microCT analysis of bone biopsies from postmenopausal osteoporotic women treated with strontium ranelate. J Bone Miner Res. 2008;23:215-222.

4. Bacchetta J, Boutroy S, Vilayphiou N, Juillard L, GuebreEgziabher F, Rognant N, Sornay-Rendu E, Szulc P, Laville M, Delmas PD, Fouque D, Chapurlat R. Early impairment of trabecular microarchitecture assessed with HR-pQCT in patients with stage II-IV chronic kidney disease. J Bone Miner Res. 2010;25:849-857.

5. Bauer JS, Link TM, Burghardt A, Henning TD, Mueller D, Majumdar S, Prevrhal S. Analysis of trabecular bone structure with multidetector spiral computed tomography in a simulated soft-tissue environment. Calcif Tissue Int. 2007;80:366-373.

6. Bell KL, Loveridge N, Jordan GR, Power J, Constant CR, Reeve J. A novel mechanism for induction of increased cortical porosity in cases of intracapsular hip fracture. Bone. 2000;27: 297-304.

7. Bell KL, Loveridge N, Power J, Rushton N, Reeve J. Intracapsular hip fracture: increased cortical remodeling in the thinned and porous anterior region of the femoral neck. Osteoporos Int. 1999;10:248-257.

8. Berger MJ, Hubbell JH, Seltzer SM, Chang J, Coursey JS, Sukumar R, Zucker DS. XCOM: Photon Cross Sections Database. Gaithersburg, MD: National Institute of Standards and Technology; 1990.

9. Black DM, Thompson DE. The effect of alendronate therapy on osteoporotic fracture in the vertebral fracture arm of the Fracture Intervention Trial. Int J Clin Pract Suppl. 1999;101: 46-50.

10. Boivin GY, Chavassieux PM, Santora AC, Yates J, Meunier PJ. Alendronate increases bone strength by increasing the mean degree of mineralization of bone tissue in osteoporotic women. Bone. 2000;27:687-694.

11. Borah B, Dufresne T, Nurre J, Phipps R, Chmielewski P, Wagner L, Lundy M, Bouxsein M, Zebaze R, Seeman E. Risedronate reduces intracortical porosity in women with osteoporosis. J Bone Miner Res. 2010;25:41-47.

12. Borah B, Dufresne TE, Chmielewski PA, Johnson TD, Chines A, Manhart MD. Risedronate preserves bone architecture in postmenopausal women with osteoporosis as measured by threedimensional microcomputed tomography. Bone. 2004;34:736-746.

13. Bousson V, Peyrin F, Bergot C, Hausard M, Sautet A, Laredo JD. Cortical bone in the human femoral neck: three-dimensional appearance and porosity using synchrotron radiation. $J$ Bone Miner Res. 2004;19:794-801.

14. Boutroy S, Bouxsein ML, Munoz F, Delmas PD. In vivo assessment of trabecular bone microarchitecture by highresolution peripheral quantitative computed tomography. J Clin Endocrinol Metab. 2005;90:6508-6515.

15. Boutroy S, Van Rietbergen B, Sornay-Rendu E, Munoz F, Bouxsein ML, Delmas PD. Finite element analysis based on in vivo HR-pQCT images of the distal radius is associated with wrist fracture in postmenopausal women. $J$ Bone Miner Res. 2008;23:392-399.

16. Boyd SK. Site-specific variation of bone micro-architecture in the distal radius and tibia. J Clin Densitom. 2008;11:424-430. 
17. Bredella MA, Misra M, Miller KK, Madisch I, Sarwar A, Cheung A, Klibanski A, Gupta R. Distal radius in adolescent girls with anorexia nervosa: trabecular structure analysis with high-resolution flat-panel volume CT. Radiology. 2008;249: 938-946.

18. Buie HR, Campbell GM, Klinck RJ, MacNeil JA, Boyd SK. Automatic segmentation of cortical and trabecular compartments based on a dual threshold technique for in vivo micro-CT bone analysis. Bone. 2007;41:505-515.

19. Burghardt AJ, Buie HR, Laib A, Majumdar S, Boyd SK. Reproducibility of direct quantitative measures of cortical bone microarchitecture of the distal radius and tibia by HR-pQCT. Bone. 2010;47:519-528.

20. Burghardt AJ, Issever AS, Schwartz AV, Davis KA, Masharani U, Majumdar S, Link TM. High-resolution peripheral quantitative computed tomographic imaging of cortical and trabecular bone microarchitecture in patients with Type 2 diabetes mellitus. J Clin Endocrinol Metab. 2010;95:5045-5055.

21. Burghardt AJ, Kazakia GJ, Laib A, Majumdar S. Quantitative assessment of bone tissue mineralization with polychromatic micro-computed tomography. Calcif Tissue Int. 2008;83: 129-138.

22. Burghardt AJ, Kazakia GJ, Link TM, Majumdar S. Automated simulation of areal bone mineral density assessment in the distal radius from high-resolution peripheral quantitative computed tomography. Osteoporos Int. 2009;20:2017-2024.

23. Burghardt AJ, Kazakia GJ, Majumdar S. A local adaptive threshold strategy for high resolution peripheral quantitative computed tomography of trabecular bone. Ann Biomed Eng. 2007;35:1678-1686.

24. Burghardt AJ, Kazakia GJ, Ramachandran S, Link TM, Majumdar S. Age- and gender-related differences in the geometric properties and biomechanical significance of intracortical porosity in the distal radius and tibia. J Bone Miner Res. 2010; 25:983-993.

25. Burghardt AJ, Kazakia GJ, Sode M, de Papp AE, Link TM, Majumdar S. A longitudinal HR-pQCT study of alendronate treatment in post-menopausal women with low bone density: relations between density, cortical and trabecular microarchitecture, biomechanics, and bone turnover. J Bone Miner Res. 2010 June 18. [Epub ahead of print].

26. Burrows M, Liu D, McKay H. High-resolution peripheral QCT imaging of bone micro-structure in adolescents. Osteoporos Int. 2010;21:515-520.

27. Burrows M, Liu D, Moore S, McKay H. Bone microstructure at the distal tibia provides a strength advantage to males in late puberty: an HR-pQCT study. J Bone Miner Res. 2010;25: 1423-1432.

28. Chappard C, Marchadier A, Benhamou CL. Side-to-side and within-side variability of 3D bone microarchitecture by conventional micro-computed tomography of paired iliac crest biopsies. Bone. 2008;43:203-208.

29. Chappard C, Marchadier A, Benhamou L. Interindividual and intraspecimen variability of 3-D bone microarchitectural parameters in iliac crest biopsies imaged by conventional micro-computed tomography. J Bone Miner Metab. 2008;26: 506-513.

30. Chapurlat RD, Delmas PD. Bone microdamage: a clinical perspective. Osteoporos Int. 2009;20:1299-1308.

31. Chavassieux P, Asser Karsdal M, Segovia-Silvestre T, Neutzsky-Wulff AV, Chapurlat R, Boivin G, Delmas PD. Mechanisms of the anabolic effects of teriparatide on bone: insight from the treatment of a patient with pycnodysostosis. J Bone Miner Res. 2008;23:1076-1083.

32. Chen H, Zhou X, Shoumura S, Emura S, Bunai Y. Age- and gender-dependent changes in three-dimensional microstructure of cortical and trabecular bone at the human femoral neck. Osteoporos Int. 2010;21:627-636.

33. Chen P, Miller PD, Recker R, Resch H, Rana A, Pavo I, Sipos AA. Increases in BMD correlate with improvements in bone microarchitecture with teriparatide treatment in postmenopausal women with osteoporosis. J Bone Miner Res. 2007;22:11731180.

34. Chevalley T, Bonjour JP, Ferrari S, Rizzoli R. Deleterious effect of late menarche on distal tibia microstructure in healthy 20 -year-old and premenopausal middle-aged women. $J$ Bone Miner Res. 2009;24:144-152.

35. Cohen A, Dempster DW, Muller R, Guo XE, Nickolas TL, Liu XS, Zhang XH, Wirth AJ, van Lenthe GH, Kohler T, McMahon DJ, Zhou H, Rubin MR, Bilezikian JP, Lappe JM, Recker RR, Shane E. Assessment of trabecular and cortical architecture and mechanical competence of bone by high-resolution peripheral computed tomography: comparison with transiliac bone biopsy. Osteoporos Int. 2010;21:263-273.

36. Cooper DM, Thomas CD, Clement JG, Hallgrimsson B. Threedimensional microcomputed tomography imaging of basic multicellular unit-related resorption spaces in human cortical bone. Anat Rec A Discov Mol Cell Evol Biol. 2006;288: 806-816.

37. Cooper DM, Thomas CD, Clement JG, Turinsky AL, Sensen $\mathrm{CW}$, Hallgrimsson B. Age-dependent change in the 3D structure of cortical porosity at the human femoral midshaft. Bone. 2007;40:957-965.

38. Cooper DM, Turinsky AL, Sensen CW, Hallgrimsson B. Quantitative 3D analysis of the canal network in cortical bone by micro-computed tomography. Anat Rec B New Anat. 2003; 274:169-179.

39. Cummings SR, Black DM, Rubin SM. Lifetime risks of hip, Colles', or vertebral fracture and coronary heart disease among white postmenopausal women. Arch Intern Med. 1989;149: 2445-2448.

40. Dalzell N, Kaptoge S, Morris N, Berthier A, Koller B, Braak L, van Rietbergen B, Reeve J. Bone micro-architecture and determinants of strength in the radius and tibia: age-related changes in a population-based study of normal adults measured with high-resolution pQCT. Osteoporos Int. 2009;20: 1683-1694.

41. Damilakis J, Adams JE, Guglielmi G, Link TM. Radiation exposure in X-ray-based imaging techniques used in osteoporosis. Eur Radiol. 2010;20:2707-2714.

42. Davis KA, Burghardt AJ, Link TM, Majumdar S. The effects of geometric and threshold definitions on cortical bone metrics assessed by in vivo high-resolution peripheral quantitative computed tomography. Calcif Tissue Int. 2007;81:364-371.

43. Diederichs G, Link T, Marie K, Huber M, Rogalla P, Burghardt A, Majumdar S, Issever A. Feasibility of measuring trabecular bone structure of the proximal femur using 64-slice multidetector computed tomography in a clinical setting. Calcif Tissue Int. 2008;83:332-341.

44. Diederichs G, Link TM, Kentenich M, Schwieger K, Huber MB, Burghardt AJ, Majumdar S, Rogalla P, Issever AS. Assessment of trabecular bone structure of the calcaneus using multidetector CT: correlation with microCT and biomechanical testing. Bone. 2009;44:976-983.

45. Ding M, Odgaard A, Linde F, Hvid I. Age-related variations in the microstructure of human tibial cancellous bone. J Orthop Res. 2002;20:615-621.

46. Dufresne TE, Chmielewski PA, Manhart MD, Johnson TD, Borah B. Risedronate preserves bone architecture in early postmenopausal women in 1 year as measured by threedimensional microcomputed tomography. Calcif Tissue Int. 2003;73:423-432. 
47. Engelke K, Graeff W, Meiss L, Hahn M, Delling G. High spatial resolution imaging of bone mineral using computed microtomography: comparison with microradiography and undecalcified histologic sections. Invest Radiol. 1993;28: 341-349.

48. Fajardo RJ, Cory E, Patel ND, Nazarian A, Laib A, Manoharan RK, Schmitz JE, DeSilva JM, MacLatchy LM, Snyder BD, Bouxsein ML. Specimen size and porosity can introduce error into microCT-based tissue mineral density measurements. Bone. 2009;44:176-184.

49. Faulkner KG, Gluer CC, Grampp S, Genant HK. Crosscalibration of liquid and solid QCT calibration standards: corrections to the UCSF normative data. Osteoporos Int. 1993;3: $36-42$.

50. Feldkamp LA, Davis LC, Kress JW. Practical cone-beam algorithm. J Opt Soc Am A. 1984;1:612-619.

51. Feldkamp LA, Goldstein SA, Parfitt AM, Jesion G, Kleerekoper $M$. The direct examination of three-dimensional bone architecture in vitro by computed tomography. $J$ Bone Miner Res. 1989;4:3-11.

52. Follet H, Bruyere-Garnier K, Peyrin F, Roux JP, Arlot ME, Burt-Pichat B, Rumelhart C, Meunier PJ. Relationship between compressive properties of human os calcis cancellous bone and microarchitecture assessed from 2D and 3D synchrotron microtomography. Bone. 2005;36:340-351.

53. Fox J, Miller MA, Recker RR, Bare SP, Smith SY, Moreau I. Treatment of postmenopausal osteoporotic women with parathyroid hormone 1-84 for 18 months increases cancellous bone formation and improves cancellous architecture: a study of iliac crest biopsies using histomorphometry and micro computed tomography. J Musculoskelet Neuronal Interact. 2005;5:356357.

54. Gasser JA, Ingold P, Grosios K, Laib A, Hammerle S, Koller B. Noninvasive monitoring of changes in structural cancellous bone parameters with a novel prototype micro-CT. J Bone Miner Metab. 2005;23(Suppl):90-96.

55. GE Healthcare. eXplore CT 120. 2010. Available at: https:// www2.gehealthcare.com:443/gehc-dpm/jsp/home/buildLinkfor channel.jsp?vcmID=f5e1fb5498e50210VgnVCM10000024dd14 03RCRD\&contentType=GEHC-PRODUCT. Accessed August 16, 2010.

56. Genant HK, Delmas PD, Chen P, Jiang Y, Eriksen EF, Dalsky GP, Marcus R, San Martin J. Severity of vertebral fracture reflects deterioration of bone microarchitecture. Osteoporos Int. 2007;18:69-76.

57. Goulet RW, Goldstein SA, Ciarelli MJ, Kuhn JL, Brown MB, Feldkamp LA. The relationship between the structural and orthogonal compressive properties of trabecular bone. J Biomech. 1994;27:375-389.

58. Graeff C, Timm W, Nickelsen TN, Farrerons J, Marin F, Barker $\mathrm{C}$, Gluer CC. Monitoring teriparatide-associated changes in vertebral microstructure by high-resolution $\mathrm{CT}$ in vivo: results from the EUROFORS study. J Bone Miner Res. 2007;22: $1426-1433$.

59. Graeff W, Engelke K. Microradiography and microtomography. In: Ebashi S, Koch M, Rubenstein E, eds. Handbook on Synchrotron Radiation 4. New York, NY: Elsevier Science; 1991: 361-405.

60. Gupta R, Grasruck M, Suess C, Bartling SH, Schmidt B, Stierstorfer K, Popescu S, Brady T, Flohr T. Ultra-high resolution flat-panel volume CT: fundamental principles, design architecture, and system characterization. Eur Radiol. 2006;16: 1191-1205.

61. Hangartner TN. Thresholding technique for accurate analysis of density and geometry in QCT, pQCT and microCT images. J Musculoskelet Neuronal Interact. 2007;7:9-16.
62. Hansen S, Beck Jensen JE, Rasmussen L, Hauge EM, Brixen K. Effects on bone geometry, density and microarchitecture in the distal radius but not tibia in women with primary hyperparathyroidism: a case-control study using HR-pQCT. J Bone Miner Res. 2010;25:1941-1947.

63. Harrigan TP, Mann RW. Characterization of microstructural anisotropy in orthotropic materials using a second rank tensor. J Mater Sci. 1984;19:761-767.

64. Hildebrand T, Laib A, Muller R, Dequeker J, Ruegsegger P. Direct three-dimensional morphometric analysis of human cancellous bone: microstructural data from spine, femur, iliac crest, and calcaneus. J Bone Miner Res. 1999;14:1167-1174.

65. Hildebrand T, Ruegsegger P. A new method for the modelindependent assessment of thickness in three-dimensional images. J Microsc. 1997;185:67-75.

66. Hildebrand T, Ruegsegger P. Quantification of bone microarchitecture with the Structure Model Index. Comput Methods Biomech Biomed Engin. 1997;1:15-23.

67. Hulme PA, Boyd SK, Ferguson SJ. Regional variation in vertebral bone morphology and its contribution to vertebral fracture strength. Bone. 2007;41:946-957.

68. Inceoglu S, Burghardt A, Akbay A, Majumdar S, McLain RF. Trabecular architecture of lumbar vertebral pedicle. Spine (Phila Pa 1976). 2005;30:1485-1490.

69. Issever AS, Link TM, Kentenich M, Rogalla P, Burghardt AJ, Kazakia GJ, Majumdar S, Diederichs G. Assessment of trabecular bone structure using MDCT: comparison of 64- and 320-slice CT using HR-pQCT as the reference standard. Eur Radiol. 2010;20:458-468.

70. Issever AS, Link TM, Kentenich M, Rogalla P, Schwieger K, Huber MB, Burghardt AJ, Majumdar S, Diederichs G. Trabecular bone structure analysis in the osteoporotic spine using a clinical in vivo setup for 64-slice MDCT imaging: comparison to microCT imaging and microFE modeling. J Bone Miner Res. 2009;24:1628-1637.

71. Issever AS, Vieth V, Lotter A, Meier N, Laib A, Newitt D, Majumdar S, Link TM. Local differences in the trabecular bone structure of the proximal femur depicted with high-spatialresolution MR imaging and multisection CT. Acad Radiol. 2002;9:1395-1406.

72. Ito M, Ejiri S, Jinnai H, Kono J, Ikeda S, Nishida A, Uesugi K, Yagi N, Tanaka M, Hayashi K. Bone structure and mineralization demonstrated using synchrotron radiation computed tomography (SR-CT) in animal models: preliminary findings. J Bone Miner Metab. 2003;21:287-293.

73. Ito M, Ikeda K, Nishiguchi M, Shindo H, Uetani M, Hosoi T, Orimo H. Multi-detector row CT imaging of vertebral microstructure for evaluation of fracture risk. $J$ Bone Miner Res. 2005;20:1828-1836.

74. Ito M, Nakamura T, Matsumoto T, Tsurusaki K, Hayashi K. Analysis of trabecular microarchitecture of human iliac bone using microcomputed tomography in patients with hip arthrosis with or without vertebral fracture. Bone. 1998;23:163169.

75. Jiang Y, Zhao J, Liao EY, Dai RC, Wu XP, Genant HK. Application of micro-CT assessment of 3-D bone microstructure in preclinical and clinical studies. J Bone Miner Metab. 2005;23(Suppl):122-131.

76. Jiang Y, Zhao JJ, Mitlak BH, Wang O, Genant HK, Eriksen EF. Recombinant human parathyroid hormone (1-34) [teriparatide] improves both cortical and cancellous bone structure. $J$ Bone Miner Res. 2003;18:1932-1941.

77. Jordan GR, Loveridge N, Bell KL, Power J, Rushton N, Reeve J. Spatial clustering of remodeling osteons in the femoral neck cortex: a cause of weakness in hip fracture? Bone. 2000;26: 305-313. 
78. Kalender WA, Polacin A. Physical performance characteristics of spiral CT scanning. Med Phys. 1991;18:910-915.

79. Kazakia GJ, Burghardt AJ, Cheung S, Majumdar S. Assessment of bone tissue mineralization by conventional $\mathrm{x}$-ray microcomputed tomography: comparison with synchrotron radiation microcomputed tomography and ash measurements. Med Phys. 2008;35:3170-3179.

80. Kazakia GJ, Hyun B, Burghardt AJ, Krug R, Newitt DC, de Papp AE, Link TM, Majumdar S. In vivo determination of bone structure in postmenopausal women: a comparison of HR-pQCT and high-field MR imaging. J Bone Miner Res. 2008;23: 463-474.

81. Keaveny TM, Morgan EF, Niebur GL, Yeh OC. Biomechanics of trabecular bone. Annu Rev Biomed Eng. 2001;3:307-333.

82. Khosla S, Riggs BL, Atkinson EJ, Oberg AL, McDaniel LJ, Holets M, Peterson JM, Melton LJ 3rd. Effects of sex and age on bone microstructure at the ultradistal radius: a population-based noninvasive in vivo assessment. J Bone Miner Res. 2006;21: 124-131.

83. Kinney JH, Haupt DL, Ladd AJ. Applications of synchrotron microtomography in osteoporosis research. Proc SPIE. 1997; 3149:64-68.

84. Kirmani S, Christen D, van Lenthe GH, Fischer PR, Bouxsein ML, McCready LK, Melton LJ 3rd, Riggs BL, Amin S, Muller $\mathrm{R}$, Khosla S. Bone structure at the distal radius during adolescent growth. J Bone Miner Res. 2009;24:1033-1042.

85. Krebs A, Graeff C, Frieling I, Kurz B, Timm W, Engelke K, Gluer CC. High resolution computed tomography of the vertebrae yields accurate information on trabecular distances if processed by 3D fuzzy segmentation approaches. Bone. 2009; 44:145-152.

86. Krug R, Burghardt AJ, Majumdar S, Link TM. High-resolution imaging techniques for the assessment of osteoporosis. Radiol Clin North Am. 2010;48:601-621.

87. Laib A, Hauselmann HJ, Ruegsegger P. In vivo high resolution 3D-QCT of the human forearm. Technol Health Care. 1998;6: 329-337.

88. Laib A, Ruegsegger P. Comparison of structure extraction methods for in vivo trabecular bone measurements. Comput Med Imaging Graph. 1999;23:69-74.

89. Lawson EA, Miller KK, Bredella MA, Phan C, Misra M, Meenaghan E, Rosenblum L, Donoho D, Gupta R, Klibanski A. Hormone predictors of abnormal bone microarchitecture in women with anorexia nervosa. Bone. 2010;46:458-463.

90. Li EK, Zhu TY, Tam LS, Hung VW, Griffith JF, Li TK, Li M, Wong KC, Leung PC, Kwok AW, Qin L. Bone microarchitecture assessment by high-resolution peripheral quantitative computed tomography in patients with systemic lupus erythematosus taking corticosteroids. J Rheumatol. 2010;37:14731479 .

91. Link TM, Vieth V, Stehling C, Lotter A, Beer A, Newitt D, Majumdar S. High-resolution MRI vs multislice spiral CT: which technique depicts the trabecular bone structure best? Eur Radiol. 2003;13:663-671.

92. Liu XS, Sajda P, Saha PK, Wehrli FW, Bevill G, Keaveny TM, Guo XE. Complete volumetric decomposition of individual trabecular plates and rods and its morphological correlations with anisotropic elastic moduli in human trabecular bone. $J$ Bone Miner Res. 2008;23:223-235.

93. Liu XS, Zhang XH, Sekhon KK, Adams MF, McMahon DJ, Bilezikian JP, Shane E, Guo XE. High-resolution peripheral quantitative computed tomography can assess microstructural and mechanical properties of human distal tibial bone. $J$ Bone Miner Res. 2010;25:746-756.

94. Lochmuller EM, Poschl K, Wurstlin L, Matsuura M, Muller R, Link TM, Eckstein F. Does thoracic or lumbar spine bone architecture predict vertebral failure strength more accurately than density? Osteoporos Int. 2008;19:537-545.

95. Macdonald HM, Nishiyama KK, Hanley DA, Boyd SK. Changes in trabecular and cortical bone microarchitecture at peripheral sites associated with 18 months of teriparatide therapy in postmenopausal women with osteoporosis. Osteoporos Int. 2010 May 11 [Epub ahead of print].

96. Macdonald HM, Nishiyama KK, Kang J, Hanley DA, Boyd SK. Age-related patterns of trabecular and cortical bone loss differ between sexes and skeletal sites: a population-based HR-pQCT study. J Bone Miner Res. 2010 June 30 [Epub ahead of print].

97. MacNeil JA, Boyd SK. Accuracy of high-resolution peripheral quantitative computed tomography for measurement of bone quality. Med Eng Phys. 2007;29:1096-1105.

98. MacNeil JA, Boyd SK. Load distribution and the predictive power of morphological indices in the distal radius and tibia by high resolution peripheral quantitative computed tomography. Bone. 2007;41:129-137.

99. MacNeil JA, Boyd SK. Bone strength at the distal radius can be estimated from high-resolution peripheral quantitative computed tomography and the finite element method. Bone. 2008;42: 1203-1213.

100. MacNeil JA, Boyd SK. Improved reproducibility of highresolution peripheral quantitative computed tomography for measurement of bone quality. Med Eng Phys. 2008;30:792-799.

101. Marjanovic EJ, Ward KA, Adams JE. The impact of accurate positioning on measurements made by peripheral QCT in the distal radius. Osteoporos Int. 2009;20:1207-1214.

102. Meganck JA, Kozloff KM, Thornton MM, Broski SM, Goldstein SA. Beam hardening artifacts in micro-computed tomography scanning can be reduced by X-ray beam filtration and the resulting images can be used to accurately measure BMD. Bone. 2009;45:1104-1116.

103. Melton LJ 3rd, Riggs BL, Keaveny TM, Achenbach SJ, Kopperdahl D, Camp JJ, Rouleau PA, Amin S, Atkinson EJ, Robb RA, Therneau TM, Khosla S. Relation of vertebral deformities to bone density, structure and strength. $J$ Bone Miner Res. 2010;25:1922-1930.

104. Melton LJ 3rd, Riggs BL, van Lenthe GH, Achenbach SJ, Muller R, Bouxsein ML, Amin S, Atkinson EJ, Khosla S. Contribution of in vivo structural measurements and load/ strength ratios to the determination of forearm fracture risk in postmenopausal women. J Bone Miner Res. 2007;22:14421448.

105. Mueller TL, Stauber M, Kohler T, Eckstein F, Muller R, van Lenthe GH. Non-invasive bone competence analysis by highresolution pQCT: an in vitro reproducibility study on structural and mechanical properties at the human radius. Bone. 2009; 44:364-371.

106. Mueller TL, van Lenthe GH, Stauber M, Gratzke C, Eckstein F, Muller R. Regional, age and gender differences in architectural measures of bone quality and their correlation to bone mechanical competence in the human radius of an elderly population. Bone. 2009;45:882-891.

107. Mulder L, Koolstra JH, Van Eijden TM. Accuracy of microCT in the quantitative determination of the degree and distribution of mineralization in developing bone. Acta Radiol. 2004;45: 769-777.

108. Muller R, Hildebrand T, Ruegsegger P. Non-invasive bone biopsy: a new method to analyse and display the threedimensional structure of trabecular bone. Phys Med Biol. 1994; 39:145-164.

109. Muller R, Ruegsegger P. Three-dimensional finite element modelling of non-invasively assessed trabecular bone structures. Med Eng Phys. 1995;17:126-133. 
110. Nazarian A, Snyder BD, Zurakowski D, Muller R. Quantitative micro-computed tomography: a non-invasive method to assess equivalent bone mineral density. Bone. 2008;43:302-311.

111. Nishiyama KK, Macdonald HM, Buie HR, Hanley DA, Boyd SK. Postmenopausal women with osteopenia have higher cortical porosity and thinner cortices at the distal radius and tibia than women with normal aBMD: an in vivo HR-pQCT study. J Bone Miner Res. 2010;25:882-890.

112. Nuzzo S, Lafage-Proust MH, Martin-Badosa E, Boivin G, Thomas T, Alexandre C, Peyrin F. Synchrotron radiation microtomography allows the analysis of three-dimensional microarchitecture and degree of mineralization of human iliac crest biopsy specimens: effects of etidronate treatment. $J$ Bone Miner Res. 2002;17:1372-1382.

113. Nuzzo S, Peyrin F, Cloetens P, Baruchel J, Boivin G. Quantification of the degree of mineralization of bone in three dimensions using synchrotron radiation microtomography. Med Phys. 2002;29:2672-2681.

114. Odgaard A, Gundersen HJ. Quantification of connectivity in cancellous bone, with special emphasis on 3-D reconstructions. Bone. 1993;14:173-182.

115. Odgaard A, Kabel J, van Rietbergen B, Dalstra M, Huiskes R. Fabric and elastic principal directions of cancellous bone are closely related. J Biomech. 1997;30:487-495.

116. Parfitt AM, Drezner MK, Glorieux FH, Kanis JA, Malluche H, Meunier PJ, Ott SM, Recker RR. Bone histomorphometry: standardization of nomenclature, symbols, and units. Report of the ASBMR Histomorphometry Nomenclature Committee. J Bone Miner Res. 1987;2:595-610.

117. Peyrin F, Attali D, Chappard C, Benhamou CL. Local plate/rod descriptors of 3D trabecular bone micro-CT images from medial axis topologic analysis. Med Phys. 2010;37:43644376.

118. Phan CM, Macklin EA, Bredella MA, Dadrich M, Flechsig P, Yoo AJ, Hirsch JA, Gupta R. Trabecular structure analysis using C-arm CT: comparison with MDCT and flat-panel volume CT. Skeletal Radiol. 2010 July 25 [Epub ahead of print].

119. Pistoia W, van Rietbergen B, Ruegsegger P. Mechanical consequences of different scenarios for simulated bone atrophy and recovery in the distal radius. Bone. 2003;33:937-945.

120. Recker R, Masarachia P, Santora A, Howard T, Chavassieux P, Arlot M, Rodan G, Wehren L, Kimmel D. Trabecular bone microarchitecture after alendronate treatment of osteoporotic women. Curr Med Res Opin. 2005;21:185-194.

121. Recker RR, Bare SP, Smith SY, Varela A, Miller MA, Morris SA, Fox J. Cancellous and cortical bone architecture and turnover at the iliac crest of postmenopausal osteoporotic women treated with parathyroid hormone 1-84. Bone. 2009;44: 113-119.

122. Recker RR, Delmas PD, Halse J, Reid IR, Boonen S, GarciaHernandez PA, Supronik J, Lewiecki EM, Ochoa L, Miller P, Hu H, Mesenbrink P, Hartl F, Gasser J, Eriksen EF. Effects of intravenous zoledronic acid once yearly on bone remodeling and bone structure. J Bone Miner Res. 2008;23:6-16.

123. Recker RR, Ste-Marie LG, Langdahl B, Masanauskaite D, Ethgen D, Delmas PD. Oral ibandronate preserves trabecular microarchitecture: micro-computed tomography findings from the oral iBandronate Osteoporosis vertebral fracture trial in North America and Europe study. J Clin Densitom. 2009;12: $71-76$.

124. Reichardt B, Sarwar A, Bartling SH, Cheung A, Grasruck M, Leidecker C, Bredella MA, Brady TJ, Gupta R. Musculoskeletal applications of flat-panel volume CT. Skeletal Radiol. 2008;37: 1069-1076.

125. Rizzoli R, Laroche M, Krieg MA, Frieling I, Thomas T, Delmas P, Felsenberg D. Strontium ranelate and alendronate have differing effects on distal tibia bone microstructure in women with osteoporosis. Rheumatol Int. 2010;30:1341-1348.

126. Ruegsegger P, Koller B, Muller R. A microtomographic system for the nondestructive evaluation of bone architecture. Calcif Tissue Int. 1996;58:24-29.

127. Salome M, Peyrin F, Cloetens P, Odet C, Laval-Jeantet AM, Baruchel J, Spanne P. A synchrotron radiation microtomography system for the analysis of trabecular bone samples. Med Phys. 1999;26:2194-2204.

128. Sansalone V, Naili S, Bousson V, Bergot C, Peyrin F, Zarka J, Laredo JD, Haiat G. Determination of the heterogeneous anisotropic elastic properties of human femoral bone: from nanoscopic to organ scale. J Biomech. 2010;43:1857-1863.

129. Scanco Medical AG. Scanco $\mu \mathrm{CT}$ 50. 2010. Available at: http://www.scanco.ch/systems-solutions/specimen-systems/uct-50. html. Accessed August 1, 2010.

130. Scanco Medical AG. Scanco XtremeCT. 2010. Available at: http://www.scanco.ch/systems-solutions/clinical-systems/xtremect. html. Accessed August 16, 2010.

131. Schneider P, Stauber M, Voide R, Stampanoni M, Donahue LR, Muller R. Ultrastructural properties in cortical bone vary greatly in two inbred strains of mice as assessed by synchrotron light based micro- and nano-CT. J Bone Miner Res. 2007;22: $1557-1570$.

132. Seeman E, Delmas PD. Bone quality - the material and structural basis of bone strength and fragility. $N$ Engl J Med. 2006;354:2250-2261.

133. Seeman E, Delmas PD, Hanley DA, Sellmeyer D, Cheung AM, Shane E, Kearns A, Thomas T, Boyd SK, Boutroy S, Bogado C, Majumdar S, Fan M, Libanati C, Zanchetta J. Microarchitectural deterioration of cortical and trabecular bone: differing effects of denosumab and alendronate. J Bone Miner Res. 2010;25: 1886-1894.

134. Sekhon K, Kazakia GJ, Burghardt AJ, Hermannsson B, Majumdar S. Accuracy of volumetric bone mineral density measurement in high-resolution peripheral quantitative computed tomography. Bone. 2009;45:473-479.

135. SkyScan. SkyScan 1172 high-resolution micro-CT. 2010. Available at: http://www.skyscan.be/products/1172.htm. Accessed August 1, 2010.

136. Sode M, Burghardt AJ, Nissenson RA, Majumdar S. Resolution dependence of the non-metric trabecular structure indices. Bone. 2008;42:728-736.

137. Sornay-Rendu E, Boutroy S, Munoz F, Delmas PD. Alterations of cortical and trabecular architecture are associated with fractures in postmenopausal women, partially independent of decreased BMD measured by DXA: the OFELY study. $J$ Bone Miner Res. 2007;22:425-433.

138. Sornay-Rendu E, Cabrera-Bravo JL, Boutroy S, Munoz F, Delmas PD. Severity of vertebral fractures is associated with alterations of cortical architecture in postmenopausal women. J Bone Miner Res. 2009;24:737-743.

139. Stauber M, Muller R. Volumetric spatial decomposition of trabecular bone into rods and plates-a new method for local bone morphometry. Bone. 2006;38:475-484.

140. Stein EM, Liu XS, Nickolas TL, Cohen A, Thomas V, McMahon DJ, Zhang C, Yin PT, Cosman F, Nieves J, Guo XE, Shane E. Abnormal microarchitecture and reduced stiffness at the radius and tibia in postmenopausal women with fractures. J Bone Miner Res. 2010;25:2296-2305.

141. Tzaphlidou M, Speller R, Royle G, Griffiths J, Olivo A, Pani S, Longo R. High resolution $\mathrm{Ca} / \mathrm{P}$ maps of bone architecture in $3 \mathrm{D}$ synchrotron radiation microtomographic images. Appl Radiat Isot. 2005;62:569-575.

142. van Rietbergen B. Micro-FE analyses of bone: state of the art. Adv Exp Med Biol. 2001;496:21-30. 
143. van Rietbergen B, Weinans H, Huiskes R, Odgaard A. A new method to determine trabecular bone elastic properties and loading using micromechanical finite-element models. $J$ Biomech. 1995;28:69-81.

144. Vico L, Zouch M, Amirouche A, Frere D, Laroche N, Koller B, Laib A, Thomas T, Alexandre C. High-resolution pQCT analysis at the distal radius and tibia discriminates patients with recent wrist and femoral neck fractures. J Bone Miner Res. 2008;23:1741-1750.

145. Vilayphiou N, Boutroy S, Sornay-Rendu E, Van Rietbergen B, Munoz F, Delmas PD, Chapurlat R. Finite element analysis performed on radius and tibia HR-pQCT images and fragility fractures at all sites in postmenopausal women. Bone. 2010;46: 1030-1037.

146. Voide R, Schneider P, Stauber M, Wyss P, Stampanoni M, Sennhauser U, van Lenthe GH, Muller R. Time-lapsed assessment of microcrack initiation and propagation in murine cortical bone at submicrometer resolution. Bone. 2009;45:164-173.

147. Waarsing JH, Day JS, van der Linden JC, Ederveen AG, Spanjers C, De Clerck N, Sasov A, Verhaar JA, Weinans H. Detecting and tracking local changes in the tibiae of individual rats: a novel method to analyse longitudinal in vivo micro-CT data. Bone. 2004;34:163-169.
148. Waarsing JH, Day JS, Weinans H. Longitudinal micro-CT scans to evaluate bone architecture. J Musculoskelet Neuronal Interact. 2005;5:310-312.

149. Walker MD, McMahon DJ, Udesky J, Liu G, Bilezikian JP. Application of high-resolution skeletal imaging to measurements of volumetric BMD and skeletal microarchitecture in ChineseAmerican and white women: explanation of a paradox. $J$ Bone Miner Res. 2009;24:1953-1959.

150. Wang XF, Wang Q, Ghasem-Zadeh A, Evans A, McLeod C, Iuliano-Burns S, Seeman E. Differences in macro- and microarchitecture of the appendicular skeleton in young Chinese and white women. J Bone Miner Res. 2009;24:19461952.

151. Xradia. MicroXCT 400. 2010. Available at: http://xradia.com/ products/microxct-400.php. Accessed August 1, 2010.

152. Yeni YN, Brown CU, Wang Z, Norman TL. The influence of bone morphology on fracture toughness of the human femur and tibia. Bone. 1997;21:453-459.

153. Zebaze RM, Ghasem-Zadeh A, Bohte A, Iuliano-Burns S, Mirams M, Price RI, Mackie EJ, Seeman E. Intracortical remodelling and porosity in the distal radius and post-mortem femurs of women: a cross-sectional study. Lancet. 2010;375: $1729-1736$. 